\title{
Trabalho, saude e subjetividade sob o olhar dos trabalhadores administrativo-operacionais de um hospital geral, público e universitário
}

| 1 Desiree Luzardo Cardozo Bianchessi, ${ }^{2}$ Jaqueline Tittoni |

Resumo: Este estudo se inscreve no campo da saúde do trabalhador, analisando o trabalho hospitalar a partir das experiências dos trabalhadores. O objetivo da investigação foi analisar o sofrimento dos trabalhadores da área administrativooperacional e as estratégias de produção de saúde, em razão da frequente ocorrência de adoecimentos e afastamentos do trabalho. O campo conceitual articula os conceitos de trabalho, saúde e subjetividade, buscando a ampliação da análise dos aspectos centrados no diagnóstico clínico. Nas estratégias metodológicas parte-se dos pressupostos da pesquisa-intervenção, utilizando o grupo-dispositivo para operar no campo, aliado às entrevistas individuais, observações nos locais de trabalho e intervenção fotográfica. As análises apontam a configuração do sofrimento do trabalhador administrativo-operacional relacionada à vivência da invisibilidade, gerada pelos embates nas relações profissionais na organização do trabalho no hospital, onde seu lugar é associado ao desvalor e à desqualificação. Os jogos de verdade no hospital mostram que o trabalho reconhecido como tendo valor está ligado à medicina e ao lugar de destaque que o saber médico ocupa historicamente no hospital. Os trabalhadores estudados sugerem vivências de impotência frente às demandas dos pacientes e familiares, considerando as limitaçōes impostas pelas políticas públicas na área de saúde. Frente aos tensionamentos originados nessas vivências, produzem estratégias ligadas à produção da saúde e ao enfrentamento do cotidiano de trabalho no hospital. A pesquisaintervenção propiciou agenciamentos múltiplos no grupo, tornando mais viável efetivar as transformaçōes necessárias nas relações de trabalho, trazendo novos sentidos e buscando outros modos de subjetivação.

> Palavras-chave: saúde do trabalhador; saúde mental; sofrimento trabalho hospitalar; subjetividade.

1 Psicóloga, Hospital de Clínicas de Porto Alegre; mestre em Psicologia Social e Institucional pela Universidade Federal do Rio Grande do Sul. Endereço eletrônico: delu64@terra.com.br

2 Professora adjunta,

Universidade Federal do Rio Grande do Sul; doutora em Sociologia. Endereço eletrônico: jaquemin@terra.com.br
Recebido em: 10/12/2008. Aprovado em: 12/08/2009. 


\section{Introdução}

O presente artigo surge do interesse em compreender os processos de adoecimento frequente dos trabalhadores no hospital, acompanhado pelo crescente e constante número de afastamentos do trabalho. Ele é fruto da experiência como psicóloga do trabalho em um hospital geral e das reflexões produzidas para a realização de uma dissertação de mestrado ${ }^{1}$ (BIANCHESSI, 2006) sobre o tema. Este estudo partiu de uma análise das informações do Serviço de Medicina Ocupacional do Hospital de Clínicas de Porto Alegre, a respeito das funções e cargos dos trabalhadores que têm adoecido com maior frequência e quais suas áreas de trabalho, no período de 2002 a 2004. A análise indicou, na época, a maior ocorrência de adoecimento nas áreas administrativo-operacional e enfermagem, sendo que os diagnósticos mais prevalentes estavam relacionados às doenças osteomusculares e psiquiátricas. Destas últimas, encontramos um total de 204 ocorrências, das quais 128 retornaram ao trabalho após um período de afastamento. Dentre estes, 56 eram da enfermagem e 72 distribuídos entre outros cargos, como: auxiliar administrativo (14 ocorrências), auxiliar de higienização (10 ocorrências), seguidos dos vigilantes e atendentes de alimentação.

A área administrativo-operacional, segundo o Plano de Cargos e Salários do hospital, é formada por cargos reconhecidos por desenvolverem atividades rotineiras e como não tendo relação direta com o paciente. Esta área compreende diversos cargos, como: auxiliares administrativos, auxiliares de higienizacão, atendentes de lavanderia, atendentes de alimentação, vigilantes, ascensoristas, entre outros. Os trabalhadores que exercem atividades nestes cargos e funções foram definidos como os principais sujeitos do estudo, priorizando-se aqueles que apareciam com maior prevalência de adoecimento. Dessa forma, a investigação se mostrou interessante e relevante, possibilitando a discussão da saúde do trabalhador de uma perspectiva menos discutida, ampliando nossa abordagem sobre a saúde mental dos trabalhadores no hospital.

O trabalho hospitalar tem sido tema de vários estudos no campo da saúde do trabalhador. Pitta (1990) sugere que o trabalho neste contexto implica permanente exposição a um ou mais fatores que podem produzir doenças ou sofrimento e que este fato decorre da própria natureza deste trabalho e de sua organização. Para a autora, o próprio objeto de trabalho - a dor, o sofrimento e a morte do outro - e as formas de organização do trabalho, essencial e continuado, contêm 
as determinantes principais do sofrimento que interagem dinamicamente e com

eficiência entre si e com outros possíveis fatores. Paradoxalmente, esse mesmo objeto de trabalho é capaz de produzir satisfação e prazer, através de mecanismos defensivos de natureza sublimatória, quando há condições facilitadoras que permitam aos trabalhadores terem suas tarefas socialmente valorizadas.

Para Seligmann-Silva (2003), o trabalho hospitalar, para o profissional da saúde, está associado a valores sociais e éticos de grande alcance, relacionados à vida, alívio de sofrimento e recuperação da saúde. Sendo assim, esta atividade pode significar o fortalecimento da identidade para estes profissionais e, consequentemente, ser positivo no sentido da promoção de saúde.

O desgaste intenso da saúde dos trabalhadores do hospital é apontado por Osório da Silva (1998) como estando relacionado à impotência frente a uma estrutura hierárquica centralizadora, à impossibilidade de agir criativamente na relação cotidiana de trabalho e às dificuldades quanto ao uso do saber prático dos trabalhadores. Além disso, podem produzir-se conflitos entre o ideal de trabalho em equipe e a organização do trabalho, gerando soluções individualizadas, corporativismos e competição acirrada entre as áreas técnicas especializadas.

Frente a estas análises, pode-se pensar que o trabalho hospitalar é um campo complexo onde se articulam aspectos da organização e do significado do trabalho na área da saúde. Este estudo se inscreve nesse campo tomando a perspectiva da saúde do trabalhador como referência e focando as experiências e as vivências dos trabalhadores, para além das situações de adoecimento apresentadas. As noções de trabalho, saúde e modos de subjetivação são importantes referências conceituais, tendo os modos de trabalhar no hospital como aspecto central da análise.

A análise do trabalho parte da afirmação de Castel (1998) de que o trabalho continua sendo referência não só econômica, mas também psicológica, cultural e simbolicamente dominante para a discussão sobre os processos de integração da sociedade e dos trabalhadores. No caso do trabalho hospitalar, ressalta-se que o hospital é o lugar social e historicamente legitimado e reconhecido para tratar das pessoas que estão doentes. Os profissionais lidam cotidianamente com os limites tênues entre vida e morte (PITTA, 1990), confrontando-se com a fragilidade do ser humano e, certamente, com sua própria fragilidade. Deste modo, o trabalho que pode implicar saúde e adoecimento está marcado pelo contato constante com a doença, a vida e a morte. 
Do ponto de vista da saúde, enfocamos a saúde como um processo que não pode ser dissociado do seu contexto, destacando os limites tênues entre a saúde e o adoecimento (CANGUILHEM, 1982; LAURELL; NORIEGA, 1989). A discussão sobre o sofrimento no trabalho está proposta a partir dos estudos de Dejours (1994) no campo da psicodinâmica do trabalho.

$\mathrm{O}$ objetivo desta pesquisa foi conhecer como se configuram o sofrimento e a produção de saúde junto a trabalhadores da área administrativo-operacional de um hospital geral, público e universitário. As vivências dos trabalhadores em situações de sofrimento e de produção de saúde foram o foco principal deste estudo.

Do ponto de vista metodológico, parte-se dos pressupostos da pesquisaintervenção (ROCHA; AGUIAR, 2003), que se coloca no âmbito das pesquisas qualitativas e participativas, buscando investigar a vida de coletividades na sua diversidade qualitativa, assumindo caráter de intervenção sócio-analítico. Neste contexto, o grupo assume função importante (BENEVIDES DE BARROS, 1997) como dispositivo de análise e transformação do trabalho, sendo entendido como um emaranhado de linhas de muitas histórias, constituído pelos regimes de enunciação e visibilidade. $\mathrm{O}$ grupo dispositivo funciona como estratégia de discussão coletiva, sendo que, aqui, foram priorizados a discussão coletiva sobre o trabalho, os modos de trabalhar, as vivências de sofrimento e de produção de saúde. A participação dos trabalhadores foi espontânea e o grupo foi constituído por três auxiliares administrativos e um vigilante. A partir da questão "como é trabalhar no hospital?", foram sendo organizados e desenvolvidos os encontros; o processo de discussão e análise teve a duração de três meses, perfazendo 13 encontros, com duração média de 1 h e 30 minutos. Além do grupo, foram realizadas entrevistas individuais com dois auxiliares de higienização que se disponibilizaram para os encontros do grupo, mas não puderam participar por razões do próprio trabalho e de afastamento por motivos de saúde. As entrevistas foram abertas e orientadas pela mesma questão lançada ao grupo; as observaçóes participativas tiveram o objetivo de aproximação do campo de estudos em termos de conhecer o ambiente, a organização e o cotidiano de trabalho dos trabalhadores estudados. Também foram realizadas observações participativas específicas nas áreas de trabalho daqueles que compuseram o grupo e na área de nutrição, quando se buscou falar com os atendentes de nutrição no próprio ambiente de trabalho, já que não houve nenhuma manifestação espontânea de participação na pesquisa. 
Aliada ao grupo, a ferramenta da fotografia teve o objetivo de buscar outras leituras possíveis do trabalho no hospital, ampliando os recursos do próprio grupo para produzir suas ideias, sendo que os trabalhadores fizeram fotografias fora do hospital a partir de situaçôes que lembrassem o hospital "fora" dele. A introdução da fotografia nessa pesquisa está baseada na metodologia da intervenção fotográfica (MAURENTE, 2005; TITTONI, 2004), usada como forma de ampliar os modos de expressão dos sujeitos da pesquisa e das discussões propostas nos grupos. A discussão sobre as fotografias deverá compor um estudo específico, não sendo explorada nesta exposição.

As informações advindas do acompanhamento do grupo, das observações participativas, das entrevistas individuais e da produção de fotografias foram analisadas tendo como referência a produção de analisadores que indicassem os modos de vivenciar as situações de adoecimento, de sofrimento e de produção da saúde. As discussões coletivas e as entrevistas individuais foram registradas e transcritas sem a indicação de seu autor, em razão do número de participantes no grupo e do risco de serem identificados em seu local de trabalho.

O projeto desta pesquisa foi aprovado em seus aspectos éticos e metodológicos, pela Comissão Científica e Comissão de Pesquisa e Ética em Saúde do Hospital de Clínicas de Porto Alegre, onde a pesquisa se realizou, sendo que o protocolo número 05-133 indica a aprovação deste estudo.

\section{Modos de trabalhar e vivenciar o hospital}

O campo da pesquisa foi constituído por fluxos intensos, já nas observaçōes realizadas nas áreas de trabalho onde se encontravam os sujeitos da pesquisa, onde se evidenciaram o ritmo intenso de trabalho, o fato de estarem sempre muito ocupados e a falta de tempo. A intensidade mostrou-se, também, nos momentos de grupo e de entrevistas, quando as vivências e experiências de cada um eram trazidas para a discussão.

No transcorrer do grupo, foram sendo construídas alternativas para o enfrentamento das situações de trabalho, gerando o que podemos chamar de "aquisições coletivas", pois referiam que estavam descobrindo e aprendendo com os outros. Na avaliação sobre o processo ocorrido, os depoimentos evidenciaram que o grupo ajudou a reformular maneiras de conduzir situaçóes com os pacientes, obter uma visão mais ampla sobre o trabalho dos outros, ao mesmo tempo em que não mais se sentiam sós com seus dilemas e problemas. 
Estudos no campo da saúde do trabalhador (HOEFEL et al., 2004; RAMOS, 2005) têm mostrado que a compreensão do adoecimento tem sido associada às características pessoais, desencadeando fatalmente um processo de culpabilização do trabalhador. Este fato ocorre tanto na relação entre os trabalhadores como entre os especialistas nesta área. A partir dessas problematizaçôes, acredita-se que as estratégias de grupo na pesquisa sobre saúde do trabalhador não se justificam apenas como técnica, mas como estratégia política que seria capaz de provocar rupturas na individualização e culpabilização, assim como de reconhecimento das produções coletivas.

Quando começam a falar no grupo sobre como é trabalhar no hospital, o que se escuta é como se fosse um turbilhão, não só pelas inúmeras atividades realizadas, mas pela intensidade do que é vivenciado. Da análise das informações geradas, foram produzidos analisadores ligados aos jogos de visibilidade e invisibilidade do lugar de trabalhador administrativo-operacional do hospital, aos jogos de poder, a importância da relação com os pacientes e os modos de produzir saúde neste trabalho que serão aprofundados, como segue.

\section{Trabalhadores na saúde e fora da saúde: o jogo da visibilidade e da invisibilidade}

"Comparo o hospital com uma novela, os astros do hospital são os médicos e enfermeiras, eles tão mais em evidência, mas a gente também faz parte dessa história." Nesta metáfora com a novela, o hospital é compreendido como um tecido embaraçado como uma rede, sendo configurado por aqueles "astros" que estão mais em evidência e por aqueles que ocupam outros lugares neste espaço.

O hospital pode ser compreendido como um campo de intensidades de forças, como uma rede tramada por múltiplos fios que representam a esperança, o medo, a fragilidade, a solidariedade, a potência, o desamparo, o cuidado, a dor, o sofrimento, a impotência, a corrida contra o tempo, a imprevisibilidade, a precisão e os ritmos acelerados de trabalho. Esses múltiplos fios também expressam os diferentes discursos que constituem o hospital como o discurso médico, da saúde, o econômico, o público, o administrativo.

Para que o médico possa executar de maneira adequada a sua função junto ao paciente, necessita do trabalho de muitos outros profissionais: a enfermeira, os auxiliares ou técnicos de enfermagem, os práticos de laboratório, os farmacêuticos- 
bioquímicos, as nutricionistas, as técnicas de nutrição, as atendentes de

alimentação, as psicólogas, as assistentes sociais, os auxiliares de higienização, os auxiliares administrativos, os vigilantes, os atendentes de lavanderia, os técnicos de raio-X, só para citar alguns dos profissionais, pois com certeza a lista é bem maior. Esta rede de relações de interdependência entre os profissionais sustenta o trabalho no hospital, apesar da visibilidade maior da figura do médico. Como refere um trabalhador: "o médico é o ser máximo dentro do hospital."

O lugar central que o médico ocupa está colocado na história do hospital, associado ao cuidar e tratar da saúde das pessoas legitimado com a introdução dos saberes da medicina no hospital já no final do século XVIII (FOUCAULT,1989). Neste estudo, ficou evidente a centralidade do saber e lugar médico na relação com os demais profissionais no hospital. Nas discussões produzidas no grupo, referiuse que, em nossa cultura, quando as pessoas pensam em hospital, relacionam-no diretamente à figura do médico e da enfermeira:

Quando tu diz que trabalha num hospital, todo mundo acha que tu é enfermeiro, as pessoas acham que no hospital só tem médicos e enfermeiros. Não tem higienização, não tem cozinheiro, não tem....(outros profissionais).

Expressões como essa indicam os jogos de verdade que constituem os sujeitos do trabalho no hospital, pois são concebidos como profissionais da saúde especificamente aqueles que têm uma qualificação formal para o exercício dessa prática, fazendo, portanto, a assistência dos pacientes. Esses são os profissionais mais valorizados no hospital, pois estão também vinculados aos objetivos-fins da organização. Os trabalhadores que ocupam outros postos de trabalho passam a ser subjetivados pela vivência de sua invisibilidade e pelo que representam, ou pensam que representam, alimentando, muitas vezes, um sentimento de desvalor.

De um modo geral, a atividade dos trabalhadores administrativo-operacionais é entendida como puramente administrativa - em suas palavras, é como se fizessem tarefas que envolvessem apenas papeis - quando na prática estão em contato permanente com os pacientes. Assim eles falam

Pressupõem que o pessoal administrativo só lida com papel e a gente lida com pessoas doentes, carentes de todas as formas. A gente se apega, tem vários colegas que não se apegam, mas isso é uma forma de proteção. Eu trabalho lá na [...], tem colegas que não suportam aquilo lá, outros ficam chorosos, irritadiços.

Nós aqui somos meio assistente social, meio psicóloga, meio relações públicas, tu ouve muito os pacientes. Eles têm mais liberdade de expressão com a gente. 
Os auxiliares administrativos, neste hospital, desempenham papel fundamental, que implica acolher, entender e auxiliar nas necessidades dos pacientes e familiares, de modo a procurar uma solução e um encaminhamento, pois estão nas recepções, secretarias de serviços e postos de enfermagem. Assim, sua atividade requer capacidade e flexibilidade para sair do administrativo-burocrático e se dispor, permanentemente, a enfrentar o inusitado, o inesperado.

Contudo, entendem que estas atribuiçõos, sua flexibilidade e empenho não são vistas, nem reconhecidas pela organização. Estas situações demonstram os modos como se institucionalizam as relaçōes de trabalho no hospital, a saber, marcadas por relações de saber-poder, hierarquizadas e disciplinares. Conforme afirma Foucault $(1989 ; 1991)$, só foi possível colocar ordem no caos do hospital a partir da tecnologia política da disciplina. Tecnologia essa que perdura até os dias de hoje, com função de organizar, dar limites, ordenar e demarcar espaços.

As vivências sobre o cotidiano de trabalho no hospital indicam efeitos nos modos de ser e de viver dos trabalhadores, apesar da aparente invisibilidade, conforme suas expressões:

Nesses dois anos que trabalho no hospital envelheci, me tornei uma pessoa mais fria... chego em casa não quero sair. Por outro lado tenho uma atitude mais ativa frente a algumas coisas, se eu vejo alguém precisando de algo, vou logo prestar socorro.

[Trabalhar no hospital] dá uma agitação na gente. Muita pressão de chefia, colegas e pacientes (estes são muito graves). Tem que criar armas para se defender, a gente acaba levando coisas [preocupaçóes] do hospital para casa.

O encontro entre estes trabalhadores e o hospital aponta para a subjetividade, considerando com Guattari e Rolnik (1996, p. 321) que a "subjetividade não é passível de totalização ou de centralização no indivíduo. [...] a subjetividade é essencialmente fabricada e modelada no registro do social.” Nardi (2004, p. 56) entende a subjetividade como resultante dos processos de interação entre indivíduos e sociedade, isto é, "da forma como o sujeito constrói-se e é construído na trama do social”. O que é vivido no hospital produz sujeitos que se mostram implicados com sua prática, solidários, sofridos, indicando que, neste trabalho é impossível sair intacto; é impossível não ser atravessado pelo que é vivido no trabalho. E principalmente indica que as vivências neste trabalho modulam particularidades, envolvendo sentimentos, valores e modos de viver.

Os trabalhadores estudados reconhecem seu papel e sua função para que a engrenagem do hospital funcione, o que fica claro no final da fala sobre o hospital 
como novela: "a gente também faz parte dessa história." Este fato remete ao que

Castel (1998) discute sobre a construção da dignidade social estar relacionada à contrapartida de sua utilidade social. Contudo, para os trabalhadores estudados, a vivência na hierarquia do trabalho hospitalar, assim como o embate com os outros profissionais faz surgir, em geral, desconfortos, desgastes e gera sentimentos de desvalia. Dessa maneira, a dignidade mostra-se ambivalente, pois eles conseguem valorizar seu trabalho e indicam o reconhecimento que vem dos pacientes, mas não identificam reconhecimento por parte da gestão e da hierarquia da organização.

O sofrimento, assim, surge pela dificuldade de reconhecimento institucional do seu trabalho, sendo essa uma das formas típicas de sofrimento reconhecidas por Dejours (1999). Isto fica reafirmado através de uma outra expressão utilizada, ao falarem da oportunidade em participar desta pesquisa, dizendo: "alguém vai ouvir nossos gritos silenciosos." Quando afirmam que seus gritos são silenciosos, estão dizendo que não se fazem escutar, estão silenciados dentro da organização. Tittoni (2004) refere que o silenciamento dos sofrimentos está relacionado com a função de proteção do trabalhador frente à ameaça da perda do emprego. Emprego que, segundo Nardi (2004) traz a possibilidade de desenvolvimento de seu trabalho e que tem por função, na nossa sociedade, ser o suporte central para manutenção e produção da vida.

\section{Tensionamentos das relações saber x poder: a sutileza da dominação}

O hospital é um lugar que, como uma organização prestadora de serviços, tem sua prática calcada na relação entre as pessoas, seja entre trabalhadores ou envolvendo pacientes e familiares. São raros os postos de trabalho em que o trabalhador do hospital poderá estar vinculado apenas a uma máquina para realizar seu trabalho. No exercício do trabalho hospitalar desencadeia-se, permanentemente, uma relação de dependência entre os diferentes trabalhadores, marcada pelas expectativas de uns com os outros e com os modos de ser de cada trabalhador. Nessas relações de dependência se acirram os jogos de saber/poder, nos quais todos estão implicados. Por exemplo, mesmo que o médico seja considerado o lugar de maior evidência no hospital ou o saber mais legitimado, ele depende dos outros profissionais para exercer seu trabalho. Além disso, essas relações de dependência também estão marcadas pelo julgamento das ações e pelos lugares de autoridade definidos nas relações de poder. 
As relações de poder, segundo Foucault (1995), são analisadas não com o objetivo de pensar o sujeito que se produz nelas e através delas. Poder e sujeito estão associados, indicando que as relações de poder que constituem o trabalho no hospital pressionam para a produção dos trabalhadores neste contexto. Foucault (1999) refere que o sujeito constitui-se a si mesmo através de um determinado número de práticas que são jogos de verdade e práticas de poder. $\mathrm{O}$ autor busca a constituição histórica das diferentes formas do sujeito, em relação com jogos de verdade, e analisa como o sujeito se constitui de forma ativa, mediante as práticas de si, as quais não são inventadas pelo indivíduo, mas, ao contrário, são esquemas que encontra na cultura e que lhe são propostos, sugeridos e/ou impostos.

Algumas cenas discutidas pelos trabalhadores apontam para o campo de forças e os jogos de poder em que estão inseridos os profissionais do hospital. Estão em jogo a vida das pessoas que estão doentes e junto a isso, os saberes de quem está empenhado em buscar alguma solução, ou pelo menos pensa e/ ou busca estar. Nesta seara, entre os vários jogos de poder que fundamentam e ordenam as práticas no hospital, a figura do médico aparece com mais autoridade para definir verdades e emitir julgamentos. Observa-se uma dinâmica onde, em geral, se dá a produção de submissão, o silenciamento pelo medo e pelo respeito à autoridade do médico, que foi traduzido, no grupo, pela expressão popular "manda quem pode, obedece quem tem juízo."

As questôes hierárquicas foram uma tônica durante todo o processo do grupo, o que demonstra a relação entre saúde mental dos trabalhadores de um hospital com a disciplina e a vivência de submissão na hierarquia. As relações com os profissionais que estão em níveis superiores da escala hierárquica são traduzidas, em geral, como autoritárias, coercitivas, permeadas por desconfianças mútuas, assim como baseadas num descrédito do seu saber. Algumas situações trazidas no grupo demonstram estas vivências:

Parece que tudo o que tu diz tem que ter o aval de alguém. Parece que o teu trabalho não é sério, não tem valor. Tudo o que tu diz tem que ir alguém atrás e dizer: é verdade. Ela sabe. Ela pode.

Geralmente as coisas vêm de cima para nós, muitas decisões que a gente tinha que participar, que a gente usa, trabalha diretamente com as coisas, só fica sabendo depois que decidiram as coisas, pô! 
As discussões sobre as relações hierárquicas apontam para o fato de existirem muitos cargos de chefia na estrutura gestora do hospital, o que parece levar os trabalhadores a disputarem uns com os outros, criando-se o que eles denominaram de "concurso de beleza" ou, em outros momentos, de "fogueira da vaidade", desenvolvendo-se um clima bastante competitivo. Segundo Foucault (2003), as relações de poder contêm positividade, no sentido de que o poder não funciona somente como uma força que diz não, mas que produz coisas, permeia, induz ao prazer, forma saber e produz discurso. Metaforicamente, falavam do quanto se sentem num jogo em que "faíscas saltam todo o tempo", exigindo que eles "aprendam a lutar com as armas que têm", conforme suas próprias palavras, para poder enfrentar as situações em que se vêem colocados. Estes modos de enfrentamento foram denominados pelos trabalhadores como "saber usar a fraseologia”. Isto é, significa buscar formas de lidar com as situações sem envolver-se tanto nelas, aspecto que discutiremos adiante.

As discussões sobre as relações hierárquicas também produziram outros sentidos, relacionados ao lugar de quem está na chefia. Eles discutiram o peso da responsabilidade dos trabalhadores que estão num nível hierárquico superior, ou mesmo ocupando cargos de chefia. $\mathrm{O}$ foco foram as pressões que recaem sobre estes trabalhadores, transformando-os em pessoas diferentes do que eram antes de ocuparem tal cargo.

Esta discussão faz pensar que algo do lugar de chefia opera no sentido do controle e da pressão - talvez até a responsabilidade por não cometer erros, tão característica do hospital - independentemente das pessoas que ocupam os cargos. Quando estes trabalhadores deixam estes cargos, também sofrem mudanças. Na discussão feita no grupo, aparecem referências a perceberem "a pessoa mais leve, mais à vontade, sem aquela carga do cargo“. É interessante a relação que um dos trabalhadores fez dessa situação com sua própria experiência, pois durante o período de realização do grupo, passou a ter um papel informal de coordenar a atividade de outras pessoas, o que lhe deu o poder de decidir algumas coisas. Este trabalhador, certo dia, estava negando um pedido de um colega em posição hierárquica inferior e pôde dar-se conta de que não precisava reagir de tal forma. Nesta situação, pode dar-se conta de que estava repetindo a situação de mando que em geral acontecia na relação dele com sua chefia. A esse 
fenômeno denominaremos de "cadeia do mando", isto é, uma sequência de ações que representam uma determinada forma de exercer a liderança, gerando reaçôes em cadeia a ponto de que aquele que um dia foi subordinado tende a repetir a forma como era tratado.

Estas reflexões estão intrincadas na problematização dos modos de subjetivar o trabalho no hospital que são forjados a partir dos modos como o trabalho e as relaçôes entre os trabalhadores foram se constituindo neste lugar. O hospital, hoje em dia, está sob o impacto das novas tecnologias e da reestruturação do trabalho, ainda que mantenha algumas das características que lhe deram origem: como definir-se como um espaço de cura, organizado por uma estrutura disciplinar e hierarquizada. Desta forma, o hospital está imerso nos modos de produção flexível, no sentido de buscar novos padrões de produtividade para, com isso, entrar na lógica do mercado de trabalho, tornando-se competitivo. Estes aspectos produzem impactos na subjetividade dos trabalhadores e nos modos de trabalhar no hospital que necessitam ser aprofundados.

\section{O encontro com os pacientes: reconhecimento $\mathrm{x}$ impotência}

O encontro com os pacientes é permanente na atividade dos trabalhadores que ocupam os cargos administrativo-operacionais no hospital e, principalmente, dos trabalhadores que fizeram parte da pesquisa. Este tema esteve sempre presente nas discussões do grupo, pois é impossível não falar nos pacientes quando da troca de experiências sobre o que fazem e vivenciam no hospital.

Os tensionamentos produzidos no contato com os próprios pacientes e seus familiares são geradores de comoção, de piedade, de indignação, de solidariedade e, algumas vezes, de uma aparente indiferença. O contato diário com a doença é muitas vezes percebido como fator fragilizador, ainda que possa também aparecer como fortalecedor, no sentido de aprender a dar mais valor a sua própria vida. Esses trabalhadores entendem que o que chamam de "fator psicológico" é uma das coisas mais difíceis do trabalho hospitalar, sendo que este "fator" pode ser traduzido como a capacidade de poder tolerar o sofrimento do outro sem se deixar abalar. Uma das participantes do grupo refere:

[...] só o que me deixa estressada é o sofrimento das pessoas, é a dor deles, é o cheiro [...] apesar de tudo eu gosto, eu sinto que ajudei de alguma maneira, eu sinto que eles saem um pouquinho mais felizes, quando a gente conversa. 
Neste hospital em específico, lida-se com uma variável que imprime outros matizes para o que se vive no hospital, que é o fato de ser um local que se destina, eminentemente, a atender os pacientes através do SUS. Isso significa, em nosso país, atender a um estrato da população brasileira com problemas sociais e econômicos gravíssimos. Desta forma, exige que os trabalhadores saibam lidar com pacientes, por exemplo, que, às vezes, não sabem ler. Além disso, referem situações de brigas entre casais e entre familiares, cujas situações os vigilantes também são chamados a intervir. Os participantes do grupo referem que, em razão destas situaçōes, certa vez uma unidade foi chamada de "Carandiru".

Podemos dizer que a doença extrapola o limite do corpo, exigindo do trabalhador do hospital e dessa organização como um todo, lidar com os modos de vida dos pacientes, pois não é possível separar o paciente daquilo que ele vive e que traz consigo quando fica internado em um hospital. Estes trabalhadores sofrem impactos importantes neste sentido, pois lhe é endereçado muitas vezes, de maneira maciça e bruta, tudo aquilo que o paciente e familiares estão vivenciando e sentindo.

Essas vivências trazem sentimentos frequentes de impotência, que faz com que os trabalhadores experimentem o sofrimento. Estão numa posição dentro da organização onde, literalmente, ficam expostos aos impactos advindos dos pacientes e usuários em geral do hospital - a chamada linha de frente. Estes trabalhadores são os primeiros a receber as pessoas que buscam o hospital, as quais, em geral, são portadoras de um nível mais elevado de ansiedade e tensão, provocados pela situação de doença. Trazem, também, uma carga psicológica que pode gerar nos trabalhadores apreensão, piedade e revolta. Essas experiências no trabalho produzem modos de subjetivação que parecem ser específicos das pessoas que vivem essas situações diariamente, pois quando falam que se tornaram diferentes depois de um tempo de trabalho no hospital, referem que uns se mostram mais sensibilizados com as situaçōes, enquanto outros chegam a um nível de sofrimento maior e outros ainda, parecem "sobreviver sem se abalar". Nas lutas diárias para enfrentar esta realidade, um dos recursos utilizados pelo trabalhador é poder contabilizar o reconhecimento que o paciente aponta pelo trabalho que fazem.

Tendo como pressuposto que as subjetivações estão relacionadas aos jogos de verdade, podemos pensar que, no que tange a trabalhar no hospital, a verdade produzida sobre o que é ser um bom funcionário indica que um bom funcionário é aquele que é capaz de suportar os impactos dessa realidade, preferencialmente sem se abalar. Se pensarmos na noção de saúde proposta por Canguilhem (1982), 
podemos pensar que enfrentar as adversidades da vida não significa simplesmente manter-se na norma, mas sobretudo consiste em inventar modos para superar o que se impõe, ser normativo.

Trabalhar no hospital, para além de ter que aprender a lidar com o sofrimento alheio e de si próprio, está relacionado também a valores sociais e éticos, conforme nos lembra Seligman-Silva (2003). Os profissionais do hospital se reconhecem como atores na promoção da vida e na produção da saúde em seu sentido mais amplo, conforme se pode observar na fala de um deles: "entendo que o trabalho que faço no hospital contribui para o desenvolvimento do meu país, para o desenvolvimento da cidadania." É neste sentido que podemos compreender o encontro dos trabalhadores que participaram desta pesquisa com os pacientes do hospital, não somente marcado pelo sofrimento, mas também pela gratificação, pela pulsão de vida e pela busca da produção de saúde.

\section{As transgressões: modos de lutas e enfrentamentos}

"Aqui no hospital a gente tem que usar a fraseologia..." A expressão fraseologia foi um termo utilizado desde o primeiro encontro do grupo, trazida por um dos integrantes. Na situação do grupo, essa expressão foi utilizada para descrever uma exigência da chefia, no que tange a saber dizer o que precisa ser dito à pessoa que está atendendo, principalmente quando a situação é de conflito. Ao afirmarmos que, no trabalho hospitalar, as relações que os trabalhadores produzem uns com os outros são um aspecto crucial, então pode-se pensar que a "fraseologia" pode indicar os modos como se controla e lida com as outras pessoas, sejam colegas, superiores ou pacientes, somente para citar alguns.

Se considerarmos que, além disso, o serviço prestado está relacionado à saúde do outro, esta "fraseologia" repercute diretamente na vida do outro. Possivelmente nestes casos, esses jogos de poder estejam também atravessados pelo fato de que "no hospital não pode haver erro", como os trabalhadores referem nas discussões em grupo não pode existir erro, na medida em que, muitas vezes, o que está em jogo é a vida e a morte. E, deste modo, intensificam-se as estratégias de controle para evitar o menor erro possível. Cabe ressaltar que os trabalhadores que participaram desta pesquisa não lidam diretamente com os riscos trazidos pelo contato direto com o paciente, assim como médicos e enfermeiras, mas estão subjetivados nos mesmos modos de funcionar o hospital. 
O grupo se apropriou do termo fraseologia e passou a utilizá-lo no transcorrer de todo o trabalho para se referir às descobertas de como fazer frente às adversidades que eles enfrentam dentro do hospital: "é saber dizer a coisa certa, na hora certa". Nestes casos, é descobrir o que precisa ser dito, como enfrentar as diferentes situações e, inclusive, investir-se de um poder que, na verdade, nem sempre têm na organização, mas perante as exigências do público externo o protege como autoridade. O modo como o grupo se apropriou da "fraseologia" também pode indicar a busca de um deslocamento da posição de assujeitamento para a de protagonista. Esta situação de protagonista está ligada às açôes no campo da saúde do trabalhador (TITTONI, 2004), onde é através das próprias vivências do trabalhador que se produzem as possíveis análises e reflexōes capazes de promover transformações. Neste caso, o próprio trabalhador pode reconhecer-se sujeito e ator de transformações possíveis.

Outro tipo de situação que surge como modo de enfrentamento das situações difíceis que precisam driblar é a chamada "burla", que significa "quebrar algumas regras" que foram prescritas em seu trabalho para, com isso, diminuir atritos entre o trabalhador e os familiares e visitantes. As regras prescritas estão relacionadas à prescrição formal do trabalho (DEJOURS, 1999), isto é, dizem respeito às instruções que estão estabelecidas sobre como o trabalho deve ser executado. Contudo, como contraponto está a organização real do trabalho, que lança mão dos modos operatórios que o trabalhador criará para poder executá-lo. Isso não está relacionado com "má intenção" e pode-se dizer que ocorre, principalmente, nas situações em que a prescrição do trabalho se dá de maneira a não contemplar os saberes práticos de quem o executará. Como também nos trabalhos dinâmicos, em que uma prescrição prévia não dá conta dos acontecimentos que se apresentam. No hospital, esta separação entre o real e o prescrito é frequente e ocorre tanto por um motivo, como pelo outro.

Os modos de luta e de enfrentamentos produzidos pelos trabalhadores apontam para nossa perspectiva sobre a saúde mental e trabalho (TITTONI, 2004, p. 74-75), que leva em consideração os "agenciamentos que implicam modos de resistência e de fuga, lutas entre poderes de conservação e de mudança, não se referindo à existência ou não de adoecimento". 
O trabalho hospitalar é vivenciado por esses trabalhadores no tensionamento da experimentação do prazer e do sofrimento no trabalho em hospital; do ponto de vista do prazer, mostram-se sentir-se úteis e valorizados por prestar um trabalho a pessoas que estão doentes, como também pelo fato de se sentirem orgulhosos por trabalhar num hospital de referência entre os hospitais da cidade. Em contraponto, experimentam o sofrimento na tensão da impotência frente às demandas dos pacientes e familiares, considerando as limitaçôes impostas pelas regras do Sistema Único de Saúde, na desvalia nos jogos de saber e poder entre os diversos profissionais dentro do hospital, nos assujeitamentos nas relações hierárquicas, que os levam a se sentirem invisibilizados na organização do trabalho no hospital.

O estudo realizado também colocou em evidência o tabu que ainda persiste sobre falar e demonstrar o sofrimento, expresso pelo próprio grupo e nas observaçōes participantes, indicando que "psicologia é coisa pra louco". Possivelmente, o fato de esta discussão ter sido proposta dentro do local de trabalho deixou ainda mais intensa esta dificuldade de falar, podendo, inclusive, ser tomado com alto grau de desconfiança. Além disso, éimportante considerar que os jogos de verdade que atuam na produção dos sujeitos do trabalho indicam que o bom funcionário é aquele que não adoece e que não "se abala" - neste caso, a discussão sobre o sofrimento poderia mostrar fragilidades num contexto onde a vivência do adoecimento profissional está marcada pela individualização da doença e, consequentemente, pela culpabilização dos trabalhadores (NARDI, 1999; HOEFEL et al., 2004).

Esses jogos de verdade funcionam como invisibilizadores/silenciadores dos sofrimentos produzidos no e pelo trabalho. Para trabalhar num hospital, independentemente do lugar ocupado, é preciso mostrar-se forte para poder fazer frente a essa atividade, que exige defrontar-se com a vida do outro e, na maioria das vezes, implica lidar com o sofrimento alheio. Então, mostrar o sofrimento pode significar uma fragilidade que não corresponde ao que é esperado de um trabalhador para esse lugar.

A configuração do sofrimento do trabalhador administrativo-operacional está relacionada à vivência da invisibilidade, gerada pelos embates nas relações com os profissionais na organização do trabalho no hospital, onde parece prevalecer seu lugar de desvalor. 
A partir dos estudos dejourianos, poderíamos dizer que o sofrimento do trabalhador administrativo-operacional do hospital se assemelha ao descrito pelo autor, como sem esperança de reconhecimento. Os participantes deste estudo fazem referência ao seu posto de trabalho como um lugar que os leva a ficarem muito expostos ao impacto psicológico que demanda o atendimento aos pacientes e usuários em geral do hospital. Como denominamos, encontram-se na "linha de frente", deparando-se cotidianamente com as pressões oriundas da organização do trabalho em confronto com as pressōes advindas do público atendido. Contudo, apesar do atendimento ao paciente, por vezes representar uma carga de sofrimento, também representa a parte do reconhecimento e gratificação.

Outro elemento importante é a forte tendência de dominação daqueles que estão na escala hierárquica superior, reforçado por relações hierárquicas rígidas, características do hospital. Dessa maneira, produzem-se modos de subjetivação (GUATTARI; ROLNIK, 1996; TITTONI, 2004) da ordem da submissão e silenciamento, onde o trabalhador que está em posição hierárquica inferior não se sente autorizado a expressar seus sentimentos e pensamentos, produzindo-se sofrimentos silenciosos que podem transformarse em sofrimentos patogênicos, conforme entendem Dejours e Abdouchelli (1994), podendo levar ao adoecimento.

Os trabalhadores participantes do grupo também revelaram como o sofrimento pode-se orientar no sentido de forjar saídas astuciosas e até mesmo transgressoras, através das lutas que representam a capacidade do trabalhador de transformar aquilo que foi prescrito em algo que produza maior bem-estar e facilidade para enfrentar as adversidades do trabalho hospitalar. Estas possibilidades apontam para a questão da saúde, concebida por Canguilhem (1982) como maneira de abordar a existência, desde a capacidade de ser normativo - isto é, criar novas normas.

A pesquisa-intervenção, enquanto prática transformadora, propiciou agenciamentos múltiplos no grupo, tornando mais viável a capacidade para efetivar as transformações necessárias nas relações de trabalho, trazendo novos sentidos, buscando outros modos de subjetivação. Modos esses não tão marcadamente caracterizados pela dominação/submissão, mas na busca da condição de protagonista, podendo experimentar-se na ordem da invenção.

Para finalizar, podemos dizer que este estudo faz pensar o hospital como lugar da diversidade, dos múltiplos discursos e marcado pelos jogos intensos de saberpoder que assumem a função de organizar a dispersão que está na diversidade. 
O hospital é vivenciado pelos trabalhadores como um tecido embaraçado como uma rede permeada por mudanças constantes e muitas vezes repentinas. Dessa forma, reafirmamos o hospital como um campo de intensidade de forças, onde a vida e a morte se encontram em encruzilhadas, albergando, para além da morte, muitas vidas - sobretudo as vidas dos trabalhadores que não estão somente de passagem. As histórias de trabalho desses profissionais, aqui sujeitos deste estudo, contam a história de muitas outras histórias dentro do hospital.

\section{Referências}

BENEVIDES DE BARROS, R. Dispositivos em ação: o grupo. In: LANCETTI, A. (Org.). Saúde e Loucura 6. São Paulo, v. 6, p. 183-191, 1997.

BIANCHESSI, D.L.C. Trabalho, saúde e subjetividade na diversidade de um hospital geral, público e universitário. 2006. 132 p. Dissertação (Mestrado em Psicologia) - Programa de Pós-Graduação em Psicologia Social e Institucional, Universidade Federal do Rio Grande do Sul, Porto Alegre, 2006.

CANGUILHEM, G. O normal e o patológico. 2.ed. Rio de Janeiro: Forense-Universitária, 1982. 270p.

CASTEL, R. As metamorfoses da questão social: uma crônica do salário. Petrópolis: Vozes, 1998. 611p.

DEJOURS, C. O trabalho entre sofrimento e prazer. In: . A banalização da injustiça social. Rio de Janeiro: Fundação Getúlio Vargas, 1999. p. 27-36.

DEJOURS, C.; ABDOUCHELI, E.; JAYET, C. Psicodinâmica do trabalho: contribuições da Escola Dejouriana à análise da relação prazer, sofrimento e trabalho. São Paulo: Atlas, 1994. 145p.

FOUCAULT, M. História da sexualidade I: a vontade de saber. 15. ed. Rio de Janeiro: Graal, 2003. 152p.

FOUCAUlT, M. La Ética Del Cuidado de si como Práctica de la Libertad. In:

Estética, ética y hermenêutica. Barcelona: Paidós, v. 3, p. 393-415, 1999.

FOUCAULT, M. Microfisica do poder. 8.ed. Rio de Janeiro: Graal, 1989. 295p.

FOUCAULT, M. O sujeito e o poder. In: DREYFUS, H. L.; RABIOW P. (Org.). Michel Foucault, uma trajetória filosófica: para além do estruturalismo e da hermenêutica. Rio de Janeiro: Forense, 1995. p. 231-249.

FOUCAULT, M. Vigiar e punir: nascimento da prisão. 8.ed. Petrópolis: Vozes, 1991. 277p.

GUATTARI, F.; ROLNIK, S. Micropolitica: cartografias do desejo. 4. ed. Petrópolis: Vozes, 1996. 327p. 
HOEFEL, M.G.L. et al. Intervenção interdisciplinar em saúde e trabalho no Hospital de

Clínicas de Porto Alegre: grupos como proposta terapêutica para o tratamento de pacientes com lesões por esforços repetitivos. In: MERLO, A.R.C. (Org.) Saúde e trabalho no Rio Grande do Sul: realidade, pesquisa e intervenção. Porto Alegre: UFRGS, 2004. p. 191-213.

LAURELL, A.C.; NORIEGA, M. Processo de produção e saúde: trabalho e desgaste operário. São Paulo: Hucitec, 1989. 333p.

MAURENTE, V.S. A experiência de si no trabalho nas ruas através da fotocomposição. 2005. 95 p. Dissertação (Mestrado em Psicologia) - Programa de Pós-Graduação em Psicologia Social e Institucional, Universidade Federal do Rio Grande do Sul, Porto Alegre, 2005.

NARDI, H.C. Saúde, trabalho e discurso médico; relação médico-paciente e o conflito capitaltrabalho. São Leopoldo: UNISINOS, 1999. 140p.

NARDI, H.C. Saúde do trabalhador, subjetividade e interdisciplinaridade. In: MERLO, A.R.C. (Org.). Saúde e trabalho no Rio Grande do Sul: realidade, pesquisa e intervenção. Porto Alegre: UFRGS, 2004. p. 43-64.

OSÓRIO DA SILVA, C. Trabalho e subjetividade no hospital geral. Psicologia Ciência e Profissão, Brasília, n. 2, ano 18, p. 26-33, 1998.

PITTA, A. Hospital: dor e morte como ofício. 2. ed. São Paulo: Hucitec, 1990. 198p.

RAMOS, M.Z. Trabalho, subjetividade e reabilitação profissional: por uma genealogia nos modos de vida. 2005. 93 p. Dissertação (Mestrado em Psicologia) - Programa de Pós-Graduação em Psicologia Social e Institucional, Universidade Federal do Rio Grande do Sul, Porto Alegre, 2005.

ROCHA, M. L.; AGUIAR, K. F. Pesquisa-intervenção e a produção de novas análises. Psicologia Ciência e Profissão, Brasília, n. 4, ano 23, p. 64-73, 2003.

SELIGMANN-SILVA, E. Psicopatologia e Saúde Mental no Trabalho. In: MENDES, R. (Org.). Patologia do trabalho. 2.ed. Atual. Ampl. São Paulo: Atheneu, 2003. p. 1.141-1.182.

TITTONI, J. Saúde mental, trabalho e outras reflexôes sobre a economia solidária. In: MERLO, A.R.C. (Org.). Saúde e trabalho no Rio Grande do Sul: realidade, pesquisa e intervenção. Porto Alegre: UFRGS, 2004. p. 65-93.

\section{Nota}

${ }^{1}$ A pesquisa contou com recursos financeiros do FIPE. 


\section{Work, health and subjectivity in the viewpoint of administrative and operational workers in a public general university hospital}

This study falls within the field of occupational health, analyzing the hospital work from the experiences of workers. The purpose of this investigation was to analyze the suffering of administrative and operational workers and the strategies of health production, due to the frequent occurrence of illnesses and absences from work. The conceptual field articulates the concepts of work, health and subjectivity, seeking the extension of the analysis of the focus in clinical diagnosis. The methodological strategies are based on the assumptions of intervention research, using the group device to operate in the field, combined with individual interviews, observations in the workplace and photographic intervention. The analyses show the configuration of the suffering of administrative and operational worker as related to the experience of invisibility, generated by collisions in labor relations in the organization of work at the hospital, where his place is associated with unworthiness and disqualification. Games of truth in the hospital show that the work recognized as having value is linked to medicine and to the prominent place medical knowledge historically occupies in the hospital. The workers studied suggest experiences of powerlessness in the face of demands of patients and families, considering the limitations imposed by public health policies. In view of the tensions generated in these experiences, they produce strategies linked to the production of health and coping with daily work in the hospital. The intervention research has provided multiple assemblages in the group, making it feasible to carry out the necessary changes in working relationships, bringing new meaning and seeking other modes of subjectivation.

> Key words: worker's health; mental health and work; suffering hospital work; subjectivity and work. 